\title{
The frequency and clinical significance of bone involvement in outer canthus dermoid cysts
}

\author{
N Sathananthan, I F Moseley, G E Rose, J E Wright
}

\begin{abstract}
Periorbital dermoid cysts should be removed because they commonly leak their irritant contents into the surrounding tissues. The underlying bone may, however, be involved in patients with dermoid cysts at the outer canthus. Computed tomography studies of $\mathbf{7 0}$ patients (43 men and 27 women, aged 30 months to 63 years, mean 29 years) with proved dermoid cysts of this type were reviewed. The lesion was always unilateral; 34 were on the left. The bone of the lateral wall and superotemporal angle of the orbit showed the following abnormalities, often in combination: pressure erosion in 61 cases and an otherwise abnormal shape, probably developmental, in 55; the dermoid cyst entered a tunnel or canal through the lateral wall in 24; a blind pit or crater in 15; and a cleft in 20; many patients also showed abnormal bone texture. These findings are extremely important for planning adequate surgery, and indicate that bony involvement is much more frequent than previously appreciated.
\end{abstract}

(Brf Ophthalmol 1993; 77: 789-794)

Dermoid cysts around the orbits may come to surgery for cosmetic reasons, but our experience, described in a previous paper, ${ }^{1}$ indicates that they should be removed because they almost invariably leak their highly irritant contents into the surrounding tissues. The orbital inflammation which ensues is often severe and intractable and makes subsequent complete removal of the cyst much more difficult.

Even primary surgery may not be simple, however. A number of scattered reports have indicated that the underlying bone may be abnormal in some patients with dermoid cysts at the outer canthus, and that this may be manifest

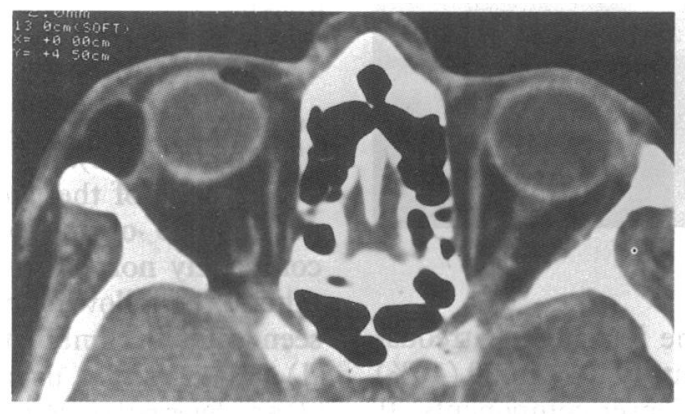

Fig $1 \mathrm{~A}$

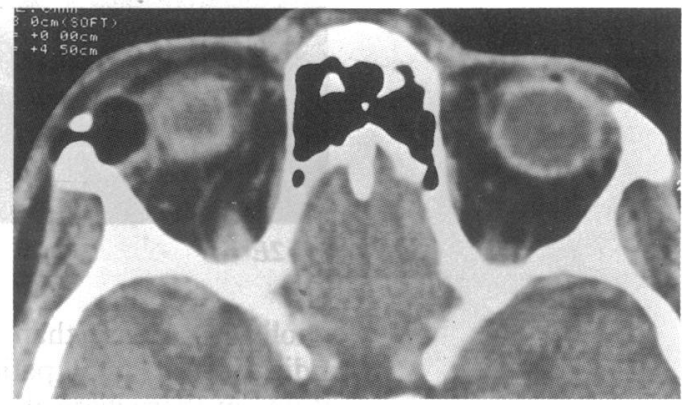

Fig $1 B$

radiologically, particularly on $x$ ray computed tomography (CT). However, the implication that this is relatively uncommon is not in accordance with our experience. Since an appreciation of the possibility of bone involvement is important when attempting complete excision of these lesions, and perhaps insufficiently emphasised in the literature, we reviewed our case material to determine the nature and frequency of osseous abnormalities.

\section{Material}

We reviewed 70 patients with adequate CT studies who had a lesion palpable at the outer canthus, histologically proved to be a dermoid cyst. The images were reviewed for the size, shape, and radiographic density of the lesion, whether it appeared primarily intraorbital or extraorbital, and whether it extended into the temporal fossa or cranial cavity. Particular attention was paid to the configuration and (where permitted by wide window imaging) the texture of the bone of the lateral wall of the orbit.

Plain films and magnetic resonance imaging (MRI) studies were available for a small number of patients.

\section{Results}

CT studies permitting adequate analysis were available for $\mathbf{4 3}$ male and 27 female patients, aged 30 months to 63 years, mean age 29 years. The outer canthus dermoid cyst was unilateral in all cases, and on the left in 34 patients. The cyst appeared mainly intraorbital, suggesting an origin within the orbit, in 26 cases $(37 \%)$ and mainly extraorbital in $14(20 \%)$, but in 30 patients $(43 \%)$ it lay both within and without the orbit, extending to the temporal fossa in 28 $(40 \%)$. The contents of the cyst were partly or

Figure 1 'Recurrent' right orbital dermoid cyst in a man aged 50. Operating via the upper lid for a 'lipoma' 10 years previously, the surgeon found that 'it extended further back than I could safely reach'. ( $A, B$ ) 2 mm computed tomography sections. A low density dermoid cyst lies mainly within the orbit, but extends through a cleft into the temporal fossa. The rather hazy capsule was found at repeat surgery to contain inflammatory tissue. Note the generalised dysplasia of the lateral wall of the orbit. 


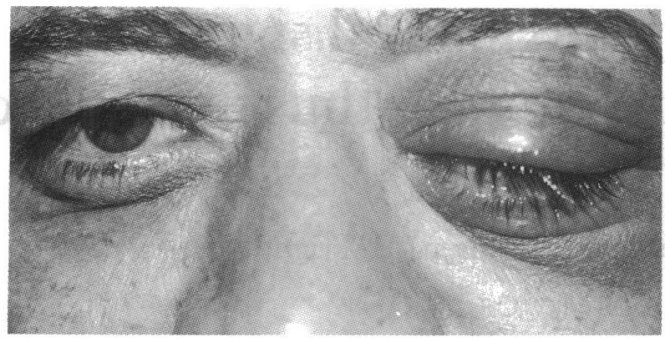

Fig $2 A$

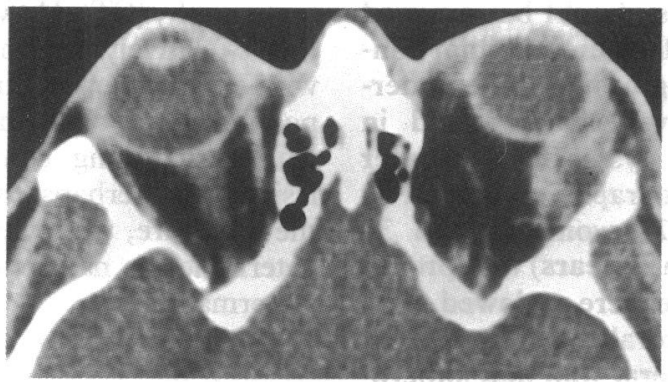

Fig $2 B$

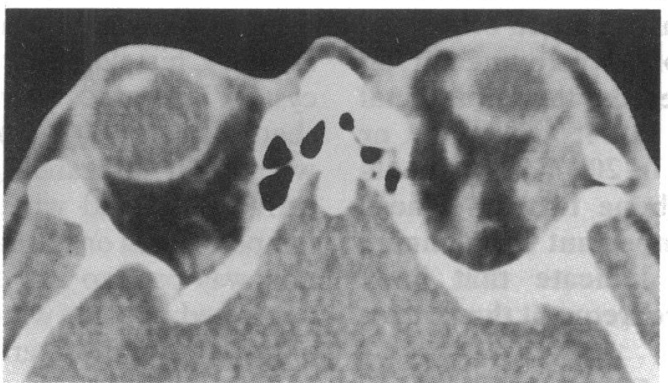

Fig 2C

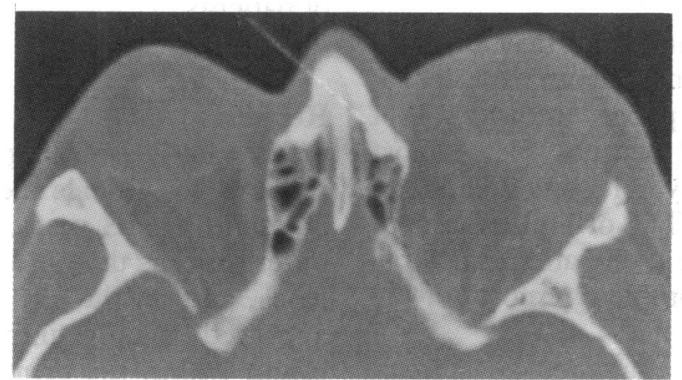

Fig $2 D$

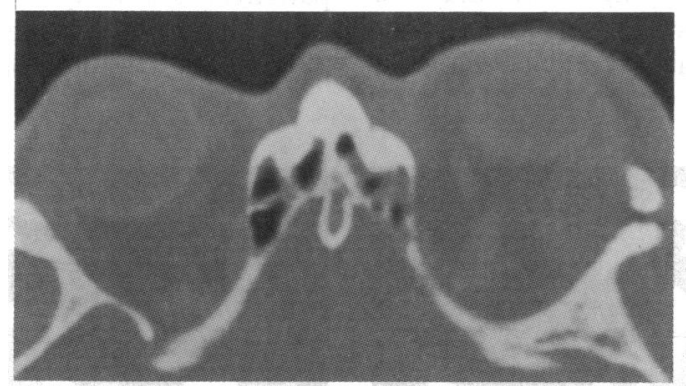

Fig $2 E$

wholly less dense than the ipsilateral vitreous, indicating fat, in 50 patients $(71 \%)$, in $20(40 \%)$ of whom there were also denser components. It was isodense with vitreous in nine patients $(13 \%)$ and generally or predominantly denser in 11 $(16 \%)$, many of whom had an associated inflammatory response. A denser circumference, presumably representing the wall of the cyst plus

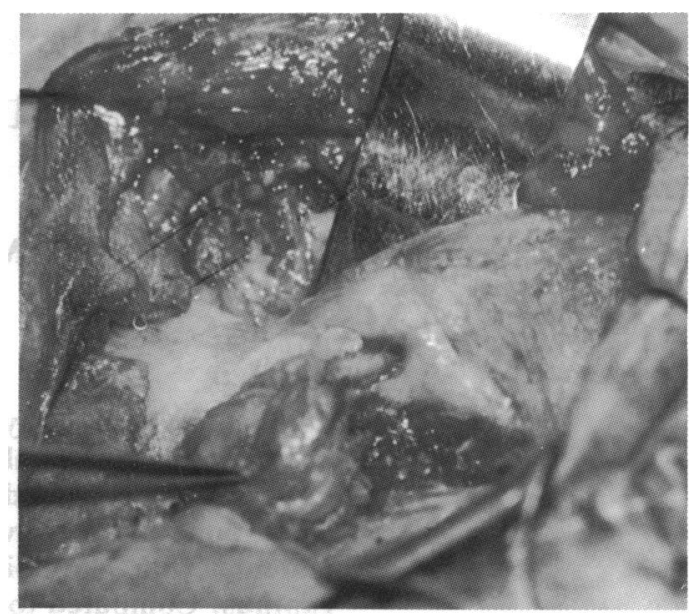

Fig $2 F$

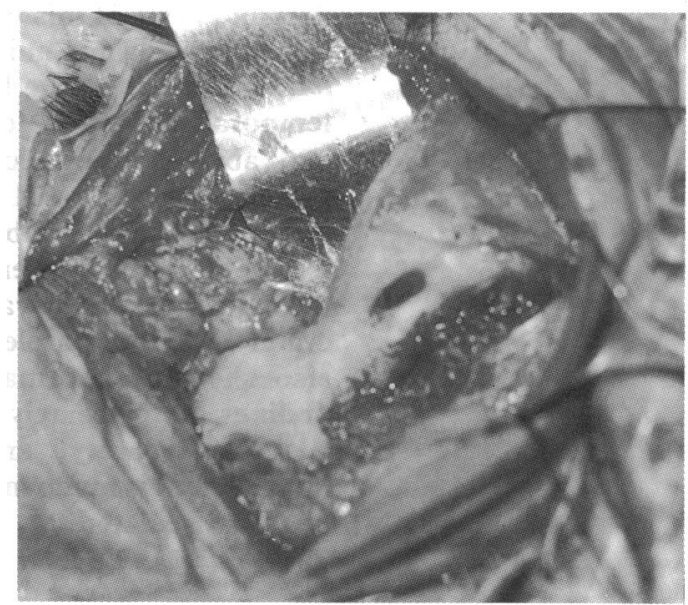

Fig $2 G$

Figure 2 A 54-year-old man presented with 2 days of left periocular pain. There was marked swelling of the lids $(A)$, with $6 \mathrm{~mm}$ relative proptosis, and eye movements were reduced. With a presumptive diagnosis of cellulitis, he was treated with systemic antibiotics. Computed tomography, however, showed a mass in the region of the lacrimal gland (B), adjacent to a tunnel in the lateral wall of the orbit; within the tunnel the tissue appeared of low density, and a further rounded area of fatty density was seen at the temporal orifice of the tunnel $(C)$. Wide window images of the same sections $(D, E)$, in addition to demonstrating the tunnel more clearly, showed the adjacent bone to be of abnormal shape and texture. Treatment was changed to non-steroidal antiinflammatory drugs and the signs resolved over 2 weeks.

Surgery confirmed the presence of a large dermoid cyst emerging into the temporal fossa from a bony tunnel $(F)$, extending through into the orbit $(G)$. There was marked inflammatory change around the lesion, which adhered to the orbital fat and lacrimal gland. The patient made a complete recovery.

compressed surrounding tissues, was visible in 49 patients $(70 \%)$.

The bone of the lateral wall and superotemporal angle of the orbit was thought to be completely normal in only one patient. In the others, the following types of abnormality were seen, often in combination:

(1) pressure erosion, usually smooth: 61 (87\%);

(2) an abnormal shape thought not to be explained by pressure erosion (Fig 1): 55 (79\%);

(3) a tunnel or canal, defined as a defect running from one surface of the bone, usually on the lateral wall of the orbit, right through to the other surface, usually in the temporal fossa, and 


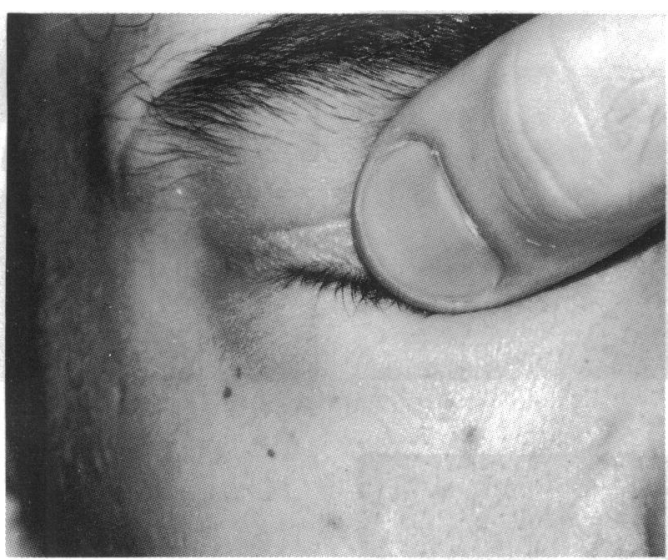

Fig 3 A left

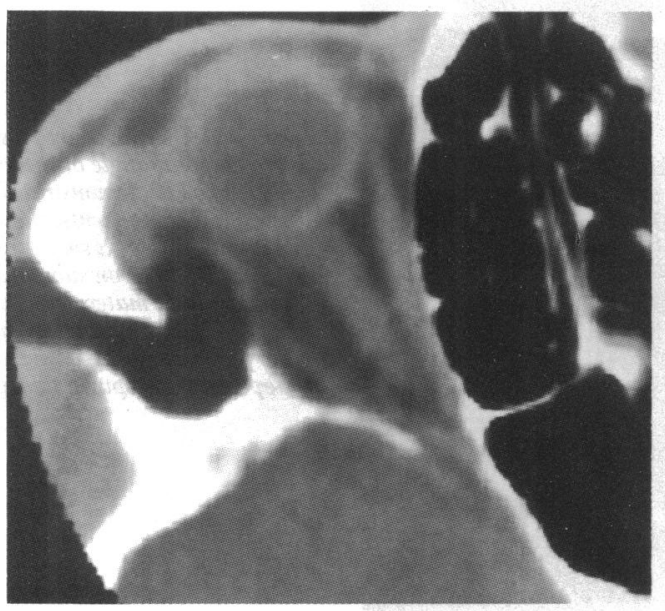

Fig $3 B$

entirely surrounded by bone (Figs 2, 3): 24 (34\%);

(4) a pit or crater: a blind canal or tunnel, running into the bone from one side, usually the orbital surface, but not reaching the other (Fig 4): 15 (21\%);

(5) a cleft: similar to a canal, but not surrounded by bone around all its circumference; usually found running transversely just deep to the lateral orbital margin, and tending to be open anteroinferiorly: 20 (29\%);

(6) abnormal texture: 13 (19\%); in a number of cases this could not be assessed, as no wide window images were available; the texture appeared abnormal in every case in which bone windows were obtained (Fig 2).

Tunnels, pits, and clefts tended to be seen in different individuals, so that $52(74 \%)$ of the patients showed some defect of this kind, associated in $47(67 \%)$ with a more widespread abnormality of the shape of the lateral wall, suggestive of maldevelopment rather than pressure effects. Despite the fact that the bone defect was often narrow, and poorly appreciated without wide window images, low density material, suggesting an extension of the dermoid cyst, was identifiable within the cleft in 41 patients $(59 \%$ overall and $79 \%$ of those with a bone defect of this type), and these extensions were confirmed at surgery (Figs $2,3)$. Three patients showed erosion through the roof of the orbit to the cranial cavity.

Plain films were useful only in the patients with major bone defects. In one patient a deep pit, running posterosuperiorly and not immediately

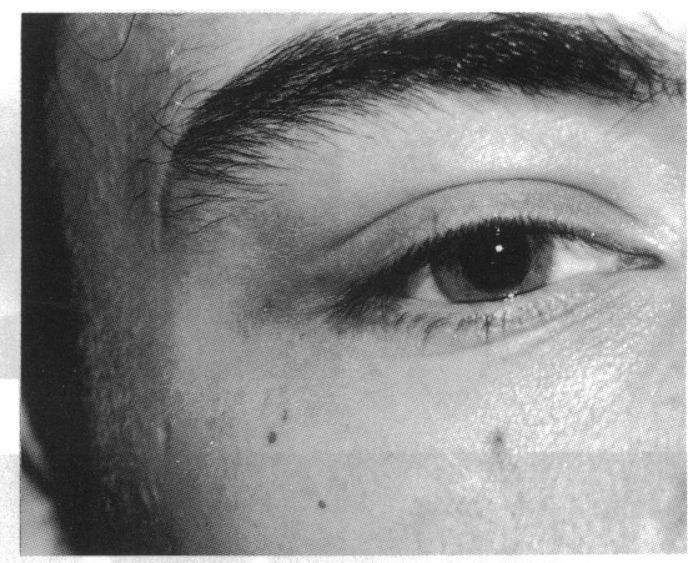

Fig $3 A$ right

Figure 3 This 19-year-old boy, with a history of juvenile rheumatoid arthritis, had undergone surgery 6 years previously for a lump at the right eyebrow, and was subsequently symptom free. He later returned complaining of headache and intermittent inflammation of the upper lid and scar. His vision became blurred when he pressed on the swollen temporal fossa. He had $2 \mathrm{~mm}$ axial proptosis, and when the eye was gently pushed posteriorly, a soft mass appeared in the temporal fossa (A). Computed tomography $(B$, oblique reformatted image) showed a complex dermoid cyst passing from the temporal fossa through a large, tortuous tunnel, into the orbit.

apparent on CT, was shown on MRI to contain material with signal characteristics identical to those of the adjacent dermoid cyst. An intraosseous prolongation of the cyst was confirmed at surgery (Fig 4).

\section{Discussion}

Ocular and orbital lesions account for half the dermoid cysts in the head and neck region, which in turn represent about $7 \%$ of those arising anywhere in the body; almost two thirds arise at the lateral border of the orbit. ${ }^{2}$ These cysts are developmental, and it was long ago suggested that the superotemporal angle of the orbit is a common site because they arise in relation to the frontozygomatic suture ${ }^{3-5}$ or to the lower end of the coronal suture; development of the fetal nasooptic groove, which occuplies this region, is particularly complex, especially laterally. ${ }^{2}$ It is not surprising, therefore, that in the presence of a dermoid cyst the bone in this region shows morphological changes suggesting anomalous development (as in almost $80 \%$ of this series), nor that it should be involved in the malformative process, as in almost three quarters of our patients.

Surgery has been carried out on lateral canthus dermoid cysts for many years: Cruveilhier recounted that Dupuytren removed a cyst from the lateral brow, intimately related to the underlying bone, whose contents had the appearance, consistency, and 'even the taste' (!) of melted butter. ${ }^{3}$ In 1847 Boyer was obliged to operate 


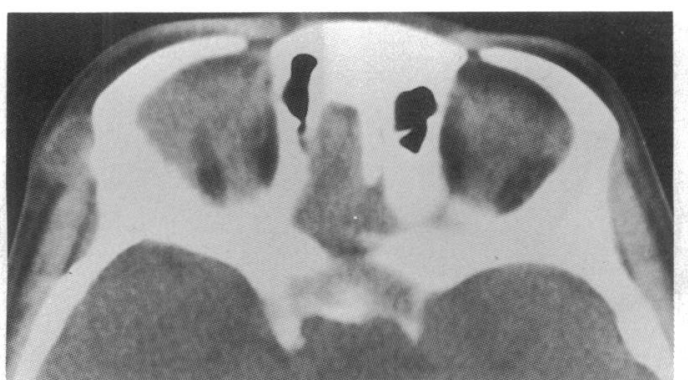

Fig 4 A

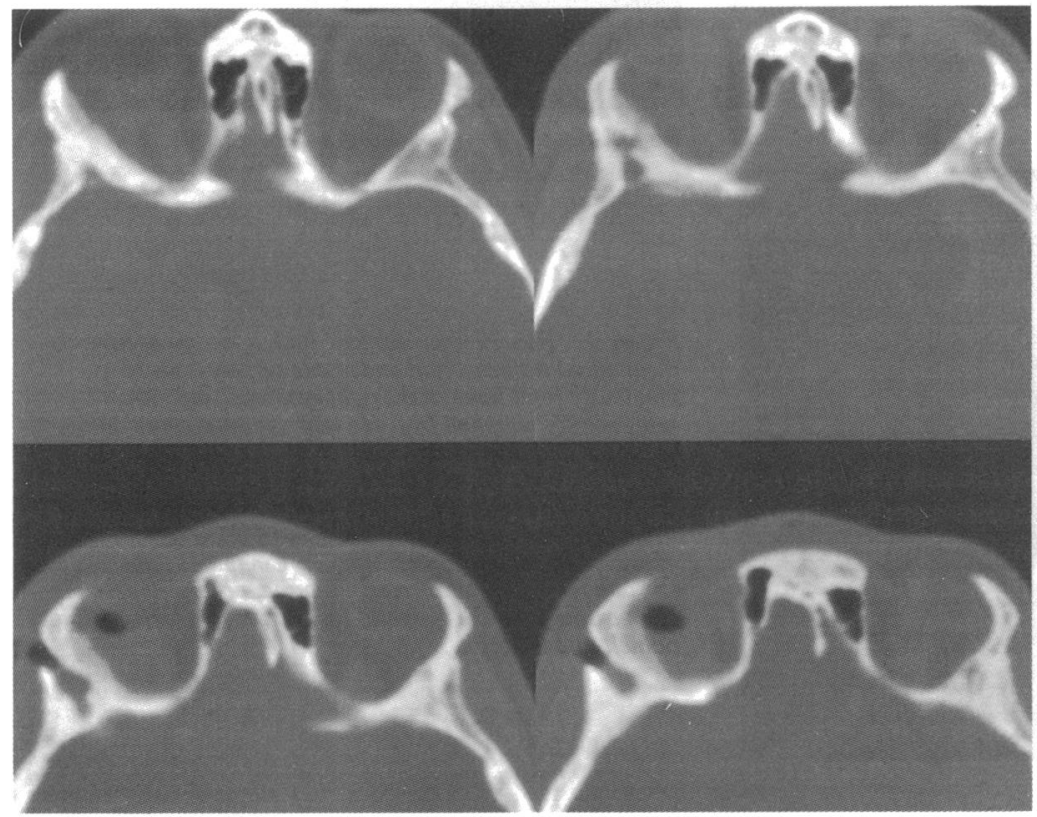

Fig 4C

three times on a 'recurrent' cyst before becoming aware that its deep portion had a genuine 'insertion' on the frontal bone, 'whose substance, compact and ulcerated, formed an irregular border around the point of fixation of the tumour' ${ }^{6}$ The presence of a 'crater', or even a full thickness bone defect (what we term a tunnel) in cases of lateral canthus and lateral orbital dermoid cyst was recognised by Régnier in 1865: 'the cyst may send a prolongation into the thickness of the frontal bone for $1-2 \mathrm{~cm}$, or even more, connected to the body of the cyst by a pedicle 2-3 mm thick . . . the channel may be so deep that the cyst develops on both sides of the bone'. ${ }^{6}$ Since that time there have been a number of case reports drawing attention to the possibility of bone involvement. ${ }^{27-10}$ The first published in the English language appears to have been in 1878 by Wagstaffe ${ }^{11}$ who, reviewing the literature, commented on the poor surgical results if the tumour were not excised in toto. Tilley $^{12}$ described a cyst which passed through the frontal bone to the dura mater, and StuartLow ${ }^{13}$ commented that 'such is the trying feature of these cases - their tendency to recur ... the method I have found so successful in these cases consists of dissecting away the cyst wall as completely as possible, and then rubbing into the exposed parts a solution containing chloride of zinc'.

Palomar Collado ${ }^{14}$ operated three times on a lateral orbital dermoid cyst, because of persistent postoperative discharge: not until pressure on

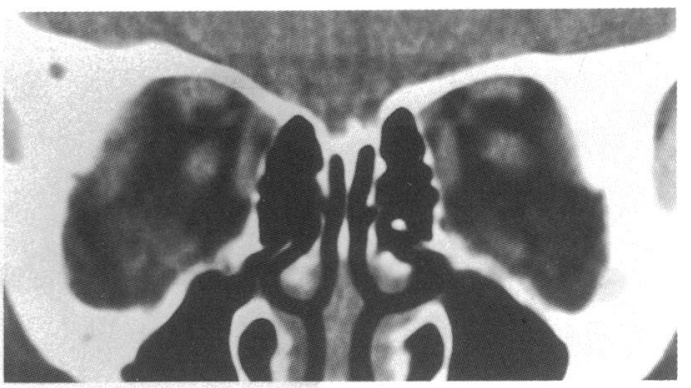

Fig $4 B$

Figure 4 A teenage boy presented with a lump at the right superotemporal angle of the orbit, which axial computed tomography $(A)$ demonstrated to have intraorbital and extraorbital components; the intervening bone was thickened. The significance of a small translucency on direct coronal imaging $(B)$, seen on subsequent magnetic resonance imaging to contain fatty material, was not appreciated initially, but when this was drilled out at surgery it was found to extend up to the periosteum on the inner surface of the frontal bone $(C$, postoperative computed tomography).

the temple (while the head was being positioned for the third operation) caused a gush of pus from the orbit, did he appreciate the existence of a tunnel in the lateral wall. Cullen ${ }^{15}$ and Pollard and Calhoun ${ }^{16}$ described patients with discharging sinuses in the temporal region associated with, but apparently distant from, orbital dermoid cysts, while Gradle ${ }^{17}$ and Carey, ${ }^{18}$ exploring masses seemingly arising in the temporal region, found them to extend deeply into the orbit, in the former case via a 'funnel-shaped hole' in its lateral wall.

The nosological and radiological waters were severely muddied by the influential paper of Pfeiffer and Nicholl, ${ }^{19}$ whose comments on the bony abnormalities were transcribed by DukeElder and others. ${ }^{20-22}$ Unfortunately, most of the eight cases they described had clinical, radiological, operative, and histological findings typi$\mathrm{cal}$ of cholesterol granulomas, ${ }^{23}$ the true nature of which had been pointed out 10 years previously. ${ }^{24}$ Indeed, they commented on what seems to have been their only genuine dermoid cyst that 'the deformity of the orbit . . . was not typical of dermoid'!

Recent discussions on the radiological changes may not be completely free of this confusion ${ }^{25-28}$; Sherman $e t a l^{2}$ commented that "bony change tends to include or extend only to the frontozygomatic suture in the case of a dermoid' (a typical finding in cholesterol granulomas ${ }^{30}$ ). However, dividing orbital dermoid cysts into superficial and deep varieties, they found one of 
four superficial lateral cysts to be associated with a 'notched supraorbital rim' and another, adherent to bone at the lateral canthus, to have a widened frontozygomatic suture. The majority of deep lateral lesions were accompanied by bone erosion. One patient had a full thickness orbit to temporal fossa bone defect and another a cleft. Benes $^{31}$ illustrated one case in which a large pit expanded the lateral wall of the orbit.

Nugent et $a l^{32}$ commented on bone abnormalities in a series of patients with periorbital dermoid cysts, 12 of which lay laterally. Their findings are rather difficult to analyse (and two lesions in the series were unconfirmed histologically), but they illustrate three patients with pressure erosion, one with a tunnel, and another with pressure erosion, abnormal shape, and a pit extending from the temporal surface of the bone and not specifically identified. The low density of the cyst contents extended into the bone defect in the patients with the pit and tunnel; the authors suggest that the latter is due to 'widening of a suture line', but it appears slightly too high and wrongly oriented to be the frontozygomatic suture, the only likely candidate. ${ }^{33}$

Symptoms and signs relating to the bone defects have been described. Whitney et $a l^{34}$ reported a patient with a 'collarstud' lesion, most of which lay within the orbit, who presented with proptosis induced by mastication: exercise of the temporal muscles forced the contents of the superficial portion of the cyst through a tunnel, shown clearly on CT, into the orbit. Another patient's degree of proptosis increased from $2 \mathrm{~mm}$ to $8 \mathrm{~mm}$ on clenching the teeth or resting the temple on the hand..$^{35} \mathrm{~A}$ man in whom CT showed an orbital dermoid cyst extending through a laterally placed tunnel, confirmed at surgery, could induce diplopia by pressure on the temple, ${ }^{36}$ while another, whose tumour appeared to have arisen in the greater wing of the sphenoid, extending medially into the orbit and lateral to the temporal fossa, could produce oscillopsia at will by chewing. ${ }^{37}$ When pressure was applied to the anterior orbit of our patient shown in Figure 3, an obvious bulge appeared at the temple.

The infrequency of intracranial spread in our series (less than $5 \%$ ) is in keeping with the findings of Ruge et $a^{38}$ who, reviewing extracranial masses in children, found 'a distinctly low incidence of intracranial extension . . . in lesions situated at the lateral aspect of the supraorbital ridge'; they illustrated one dermoid cyst with a large pit in the outer surface of the squamous temporal bone, but did not comment on what appeared to be an outer canthus tunnel at the site of the frontozygomatic suture in the same patient.

The bony anomalies are of much more than academic interest. Firstly, despite the developmental nature of the dermoid cyst, patients may be in adult life when they present with an acute inflammatory reaction, due presumably to leakage of cyst contents (Fig 2). In such circumstances, inflammatory tissue may largely obscure the capsule and low density contents which otherwise characterise this lesion on CT, each identifiable in about $70 \%$ of our patients, but recognition of the typical bony anomalies should facilitate correct diagnosis and appropriate management.

Secondly, and of more general application, preoperative awareness of the likelihood of bony involvement is, we believe, essential for proper conduct of surgery (Fig 1). It is essential that when a dermoid cyst is excised all the epithelial lining should be removed. If any epithelium is allowed to remain, it continues to secrete highly irritant material which produces severe orbital inflammation. These 'recurrent dermoids' also usually become infected, and the resulting abscess and sinus formation produces considerable scarring, which renders excision of the epithelium, now buried, extremely difficult.

\section{IMPLICATIONS FOR MANAGEMENT}

This review shows that the majority of dermoids in and around the lateral part of the orbit extend into the bone, and that many reach the temporal fossa. It is essential that, in planning his approach, the surgeon is fully aware of the true extent of the lesion. Ideally, consultation with the radiologist will ensure that adequate exposure is obtained. Unless bone involvement is limited and very anterior, removal of the lateral wall of the orbit is required to enable the whole dermoid cyst to be dissected free. Meticulous dissection of any extension to the temporal fossa, combined with drilling out any tunnels or clefts in the bone (Fig 4), will ensure that all the epithelium is removed. This will avoid the situation we have encountered on a number of occasions, where a surgeon has removed the presenting orbital portion of the cyst and left its deeper or extraorbital portions untouched, when disastrous inflammation, with abscess and sinus formation, ensued.

Many recent articles on the operative aspects of lateral canthus and lateral orbital dermoid cysts, although pointing out that the cyst may be attached to the periosteum, ${ }^{39}$ do not specifically address extension of the tumour into the bone, ${ }^{40}$ probably because the frequency of bony involvement has been underestimated. Since we believe it extremely important to be forewarned of the presence and extent of bony involvement, we recommend that appropriate imaging be carried out in all cases of suspected dermoid cyst, except perhaps when the lesion is both superficial and mobile in all directions; limited mobility probably indicates fixation to bone. ${ }^{11}$ Ultrasonography can show the cyst to extend through a major bone defect, but is blind to most of the small but surgically important intraosseous extensions shown with such clarity by CT, and not evident on plain films; we would therefore disagree strongly with the suggestion that CT (or $M R I$ ) is indicated only 'in the presence of large lesions with retrobulbar extension and bony erosion. $^{41}$

\footnotetext{
1 Lane CM, Ehrlich WW, Wright JE. Orbital dermoid cyst. Eye 1987; 1: 504-11.

2 New GB, Erich JB. Dermoid cysts of the head and neck. Surg Gynecol Obstet 1937; 65: 48-55.

3 Vassaux G, Broca A. Contribution a l'étude des kystes à contenu huileux. Arch d'Ophtalmol 1883; 3: 318-42.

4 de Lapersonne F. Kyste dermoïde fronto-orbitaire. Arch d'Ophtalmol 1893; 13: 657-62.

5 Cange A, Argaud R. Le kyste dermoïde orbito-temporal Arch d'Ophtalmol 1923; 40: 585-96.
} 
6 Cange A. Les formes cliniques des kystes dermoïdes de l'orbite et du pourfour arbitaire Arch d'Ophralmol 1924; 41 : et du

7 Doyne RW. Dermoid tumour of the orbit. Ophthalmol Rev 1896; 15: $97-100$.

8 Raueiser A. Uber kommunizierende extra- und intraorbitale Dermoide. (Zwerchsackdermoide der Orbita.) Klin Monatsbl Augenheilkd 1919; 63: 118-29.

9 Verebély T. Die Dermoidcysten der Orbita und Umgebung. Zentralbl Ophthalmol 1928; 20: 130.

10 Macdonald R, Byers JL. Dermoid tumor of the orbit simulating a neoplasm. Am $f$ Ophthalmol 1959; 47: 863-6.

11 Wagstaffe WW. Congenital dermoid cysts occurring in the branchial, and other clefts. Trans Pathol Soc London 1878; 30: 194-205.

12 Tilley $H$. Child in whom a suppurating dermoid cyst has been removed from the lower central region of forehead. Proc Roy Soc Med (Laryngol) 1919: 193-4.

13 Stuart-Low $W$. In discussion of paper by Tilley (qv)

14 Palomar Collado F. Quiste dermoide orbito-temporal. $R e v$ Méd Barcelona 1928; 9: 99-112.

15 Cullen JF. Orbital diploic dermoids. BrF Ophthalmol 1974; 58 : 105-6.

16 Pollard ZF, Calhoun J. Deep orbital dermoid with draining sinus. Am 7 Ophthalmol 1975; 79: 310-3.

17 Gradle HS. An unusual cyst of the forehead and orbit. Am $\mathcal{X}$ Ophthalmol 1929; 12:28-9.

18 Carey PC. Epidermoid and dermoid tumours of the orbit. Brf Ophthalmol 1958; 42: 225-39.

19 - Pfeiffer RL, Nicholl RJ. Dermoid and epidermoid tumors of the orbit. Arch Ophthalmol 1948; 40: 639-64.

20 Duke-Elder S. Textbook of ophthalmology. Vol V. The ocular adnexa. London: Lloyd-Luke, 1952: 4763-6.

21 Grove AS. Giant dermoid cysts of the orbit. Ophthalmology 1979; 86: 1513-20.

22 Bickler-Bluth ME, Cutler PL, Smith ME. Giant dermoid cyst of the orbit. Arch Ophthalmol 1987; 105: 1434-5.

23 Rowland Hill CA, Moseley IF. Imaging of orbitofrontal cholesterol granuloma. Clin Radiol 1992; 46: 237-42.

24 Kreibig W. Zur Kenntnis seltener Orbitaltumoren. Zeitschr Augenheilkd 1939; 95: 113-28.

25 Ossoinig KC. The role of clinical echography in modern diagnosis of periorbital and orbital lesions. In: Proceedings of the 3rd international symposium on orbital disorders. Amsterdam: W Junk, 1957: 496-540.
26 Ruchman MC, Stefanyszyn MA, Flanagan JC, González CF, Becker MH. Orbital tumors. In: González CF, Becker MH, Becker MH. Orbital tumors. In: González CF, Becker MH, Flanagan JC, eds. Diagnostic imagi

York: Springer, 1986: 201-38.
27 Pérez Moreira JV. Patologia orbitaria: exploración, diagnóstico y cirugia. Barcelona: Pujades, 1986: 198-206.

28 Gabilov GA, Sokolova ON, Cherekaev VA, Parfenova ND, Shakhud KY. Dermoid cysts of the orbit spreadin into the cranial cavity. Zhur Vopr Neyrokhir 1989; 5: 49-51.

29 Sherman RP, Rootman J, Lapointe JS. Orbital dermoids: clinical presentation and management. $\mathrm{Br} \mathcal{f}$ Ophthalmol 1984; 68: 642-52.

30 Lloyd GAS. Cholesterol granulomas of the facial skeleton. Br F Radiol 1986; 59: 481-5.

31 Benes SC. Computed tomography of the orbit. In: González CF, Grossman CB, Masdeu JC, eds. Head and spine imaging. New York: Wiley, 1985: 577-635.

32 Nugent RA, Lapointe JS, Rootman J, Robertson WD, Graeb DA. Orbital dermoids: features on CT. Radiology 1987; 165: D75-8.

33 Waddington MM. Atlas of the human skull. Rutland, Vermont: Academy Books, 1981: 4-10.

34 Whitney CE, Leone CR, Kincaid MC. Proptosis with mastication: an unusual presentation of an orbital dermoid cyst. Ophthalmic Surg 1986; 17: 295-8.

35 Bullock JD, Bartley GB. Dynamic proptosis. Am f Ophthalmo 1986; 102: $104-10$.

36 Samuelson TW, Margo CE, Levy MH, Pusateri TJ Zygomaticofrontal suture defect associated with orbital dermoid cyst. Surv Ophthalmol 1988; 33: 127-30.

37 Knight RT, St John JN, Nakada T. Chewing oscillopsia. A case of voluntary visual illusions of movement. Arch Neurol case of voluntary

38 Ruge JR, Tomita T, Naidich TP, Hahn YS, McLone DG. Scalp and calvarial masses of infants and children. Neurosurgery 1988; 22: 1037-42.

39 Kersten RC. The eyelid crease approach to superficial lateral dermoid cysts. F Pediatr Ophthalmol 1988; 25: 48-51.

40 Kronisch JW, Dortzbach RK. Upper eyelid crease surgical approach to dermoid and epidermoid cysts in children. Arch Ophthalmol 1988; 106: 1625-7.

41 Berges O, Bilaniuk LT. Orbital ultrasonography: ocular and orbital pathology. In: Newton TH, Bilaniuk LT, eds. Radiology of the eye and orbit. New York: Raven Press, 1990: 7.1-7.26. 